\title{
¿Cómo se debería abordar hoy la sostenibilidad en la educación universitaria?
}

\section{SOUTH} SUSTAINABILITY

\author{
Citar como: Vallaeys, F. (2020). \\ «¿Cómo se debería abordar hoy \\ la sostenibilidad en la educación \\ universitaria?». South Sustainability, \\ 1(1), e002. \\ DOI: 10.21142/SS-0101-2020-002
}

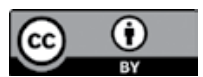

(c) El autor, 2020. Publicado por la Universidad Científica del Sur (Lima, Perú)

${ }^{*}$ E-mail de correspondencia: f.vallaeys@up.edu.pe
El mundo ha cambiado, la tecnología ha cambiado, pero el modelo educativo no había cambiado antes de la pandemia de la COVID-19, cuando llegó la obligación rápida de desarrollar la enseñanza virtual, salir de la situación de casi analfabetismo digital de los profesores y administrativos universitarios, que todavía masivamente antes preferían la enseñanza presencial tradicional, con escasa presencia de las tecnologías de la información y la comunicación (TIC) y de las posibilidades del Internet.

A pesar de todos los componentes negativos, dicha crisis pandémica tiene indudablemente un aspecto muy positivo en términos de sostenibilidad del quehacer universitario, que no dudaba en emitir masivamente dióxido de carbono $\left(\mathrm{CO}_{2}\right)$ en cada congreso, al hacer venir a ponentes del otro lado del mundo para intervenir 15 minutos en un panel. Ojalá que la parada brutal de viajes aéreos, y los beneficios económicos y ambientales que trae, haga reflexionar luego a los directivos universitarios para un empleo mayor de la virtualidad y un uso menor de los desplazamientos. Lo mismo se debería aplicar en los transportes cotidianos de estudiantes y personal, que en buena cuenta se podrían evitar o limitar, al pasar al teletrabajo y tareas académicas remotas.

Sin embargo, esta crisis pandémica no nos enseñará nada para el futuro si no enmarcamos la gestión universitaria global (académica y administrativa) dentro de una política transversal de responsabilidad social universitaria (RSU) y sostenibilidad. En la universidad, la sostenibilidad es primero un tema transversal. Desde la academia se tiene que gestionar como problemática investigativa básica, como problemática formativa y obviamente como problemática de extensión. Al comprometer a todos los actores, la dirección de RSU de cada institución de educación superior (IES) debería estar encargada de diseñar las políticas de sostenibilidad.

También la sostenibilidad debe ser considerada en su vertiente social, ya que no se puede ser «sostenible» excluyendo a partes importantes de la población de los beneficios del acceso a la educación superior, los beneficios de la ciencia, los beneficios de la justicia, los derechos, el bienestar y la seguridad social. Por otro lado, hay que tener en cuenta su vertiente económica, ya que no se puede ser sostenible si solo se gasta dinero en proyectos y nunca se obtienen ingresos para mantener justamente la acción de sostenibilidad. Por ello, el retorno económico de las inversiones en sostenibilidad debe ser una consideración importante al momento de definir políticas y estrategias. 
En la Unión de Responsabilidad Social Universitaria Latinoamericana (Ursula) nos gusta presentar todo este concepto complejo de sostenibilidad en forma de U3S: la Universidad Saludable, Solidaria y Sostenible, que logra, desde la misma administración cotidiana de su campus, enseñar a través del ejemplo la ética que nos toca profundizar para el siglo XXI: el cuidado de la salud de las personas, la sociedad y el planeta, con solidaridad entre el centro y las periferias sociales, con sostenibilidad en todas las actividades humanas regenerativas de la habitabilidad del planeta, en lugar de destructivas como en el modelo económico heredado de los siglos XIX y XX.

Ahora bien, para el caso específico del Perú, el estado del desarrollo sostenible es muy contradictorio. Hay muy buenos proyectos piloto de gente que ha entendido que en la fuente de las culturas originarias del Perú se encuentra el sentido de la sostenibilidad y, por lo tanto, del desarrollo sostenible. $Y$ al mismo tiempo somos un país muy poco sostenible, profundamente desigual y extractivista, al punto, por ejemplo, que no existe un partido ecologista, pues los políticos ven el tema como la «última rueda del coche», o que en la vida cotidiana urbana nadie tenga costumbres sostenibles (quien detiene su carro deja el motor prendido, etc.). Los temas climáticos y ecológicos parecen ser asuntos lujosos que vienen de los países del norte, pero que no nos tocan a nosotros desde el sur. En definitiva, somos una sociedad que ha tenido a los incas y a los pueblos selváticos como inspiradores originarios de una vida profundamente en armonía con la naturaleza, pero que ha girado brutalmente hacia la modernidad industrial, extractivista y agroindustrial más tosca, con ninguna responsabilidad hacia los impactos de las actividades económicas y muy poca fortaleza de la gestión pública para fiscalizar, orientar, prohibir, castigar e innovar.

Esta esquizofrenia es patente entre, por un lado, una cultura ancestral sostenible y que tiene mucho futuro a través, por ejemplo, de la cocina basada en el enfoque cultural, el turismo ecológico, la agroecología local y de exportación, y, por otro lado, la aculturación y una alienación totales frente a estas raíces, llevadas hacia un vergonzoso productivismo y consumismo individualista, con ningún cuidado de lo público, como lo constatamos en las interacciones sociales urbanas, y que se multiplica por una pésima gestión pública del desorden público. Estos dos Perú deben reconocerse y sanarse en una política nacional de progreso hacia la sostenibilidad.

En mi opinión, el desarrollo sostenible del Perú se encuentra cuando el país reconecta consigo mismo. Cuando el Perú se mira a sí mismo, se aprecia a sí mismo y se desarrolla a sí mismo. Por eso tengo mucha fe, por ejemplo, en los impactos positivos sociales del auge de la cocina peruana, porque no es un boom de algunos que se enriquecen en forma aislada destruyendo el entorno para todos los demás, sino un boom basado en un orgullo nacional y en una atención a todas las fuentes diversas del Perú, y cómo ellas pueden servir de ejemplo mundial, universalizarse, alcanzar a ser la mejor cocina del mundo. Ahí está la clave del desarrollo sostenible en el Perú, un país orgulloso de lo que es y que se mira a sí mismo para encontrar desde y a partir de su riqueza interna lo universal que puede aportar al mundo. Para cuidarse, el Perú tiene que amarse, y para amarse, tiene que sentir, contra los siglos de discriminación y maltrato colonial y poscolonial, que tiene un valor único en el mundo, valor cultural, geográfico, histórico, ecológico, que puede desembocar en actividades económicas lucrativas sin ser depredadoras, sino regenerativas.

Este objetivo de política nacional de sostenibilidad tiene que encarnarse en una política universitaria basada los artículos 124 y 125 de la Ley Universitaria peruana: una política de RSU. Creo que el primer punto debería ser que cada universidad en el Perú vaya calculando su huella ecológica desde los campus. La ventaja del cálculo de la huella ecológica es que constituye una herramienta a la vez de investigación y de acción, porque obviamente una universidad que calcula su huella ecológica se dará cuenta de que no es sostenible, que gasta los recursos del equivalente de 1,5 planetas o incluso de dos o de tres planetas. Esto obviamente conduce de inmediato a tomar medidas para ver en qué aspectos somos insostenibles. Tenemos precisamente el gran ejemplo de la Universidad Nacional de San Agustín de Arequipa (UNSA, 2018), que ha suprimido los plásticos y el tecnopor de su campus. Del mismo modo, hay que incentivar la práctica de la permacultura en los campus universitarios, aprovechando cada metro cuadrado para producir con alta tecnología y ciencia sistémica la mayor cantidad posible de comida orgánica, lo que beneficia a todos los estudiantes con alimentación casi gratuita, desde su mismo esfuerzo autónomo de producir ellos mismos su alimentación diaria. Tras cultivar más de 3000 tipos de papas, creo que el pueblo peruano es capaz de este reto en sus campus universitarios. Sencillamente hay que ir en esa dirección, consagrada en la Ley Universitaria peruana en su capítulo dedicado a la RSU. La ley lo exige, los universitarios lo pueden hacer, el contexto planetario nos urge hacerlo. ¿Qué esperamos?

\section{Referencias bibliográficas}

UNSA. (2018). «Resolución de Consejo Universitario n.o 699-2018». Disponible en: https://www.unsa.edu.pe/ wp-content/uploads/2018/01/RESOLUCIN-DE-CONSEJOUNIVERSITARIO-N-699-2018.pdf 